\title{
On solving general split equality variational inclusion problems in Banach space
}

\author{
J. Zhao ${ }^{\mathrm{a}, *}$, Y. S. Liang \\ ${ }^{a}$ College of Sciences, Qinzhou University, Qinzhou, Guangxi 535000, P. R. China. \\ ${ }^{b}$ Guangxi Key Laboratory of Universities Optimization Control and Engineering Calculation, and College of Sciences, Guangxi \\ University for Nationalities, Nanning, Guangxi 530006, P. R. China.
}

Communicated by S. S. Chang

\begin{abstract}
In this paper, we are concerned with a new iterative scheme for general split equality variational inclusion problems in Banach spaces. We also show that the iteration converges strongly to a common solution of the general split equality variational inclusion problems (GSEVIP). The results obtained in this paper extend and improve some well-known results in the literature. (C) 2017 All rights reserved.
\end{abstract}

Keywords: General split equality variational problems, strong convergence, Banach space. 2010 MSC: 47J22, 34A60.

\section{Introduction}

Many problems in physics, optimization, and economics reduce to find a solution of an equilibrium problem. Some methods have been proposed to solve the equilibrium problem; see for instance $[1,4,6,9$, $12,14-17,20,24]$.

Let $\mathrm{H}_{1}$ and $\mathrm{H}_{2}$ be real Hilbert spaces with the inner product $\langle\cdot, \cdot\rangle$ and the norm $\|\cdot\| \cdot \mathrm{C}_{1}$ and $\mathrm{C}_{2}$ are two nonempty closed convex subsets of $\mathrm{H}_{1}$ and $\mathrm{H}_{2}$, respectively. If $A: \mathrm{H}_{1} \rightarrow \mathrm{H}_{2}$ is a bounded linear operator, the split feasibility problem (SFP) is defined as follows: find $x^{*} \in \mathrm{C}_{1}$ such that

$$
A x^{*} \in C_{2} .
$$

In 1994, Censor and Elfving [3] firstly introduced the (SFP) in finite-dimensional spaces for modeling inverse problems which arise from phase retrievals and in medical image reconstruction [2]. It has been found that the (SFP) can also be used in various disciplines such as image restoration, computer tomograph and radiation therapy treatment planning [4,5]. The (SFP) in an infinite-dimensional real Hilbert space can be found in [22-24].

\footnotetext{
*Corresponding author

Email addresses: jingzhao100@126.com (J. Zhao), 1245470565@qq.com (Y. S. Liang)
} 
Recently, Moudafi and Al-Shemas introduced the following split equality feasibility problem (SEFP): to find $x \in C_{1}, y \in C_{2}$ such that

$$
\mathrm{Ax}=\mathrm{By},
$$

where $A: \mathrm{H}_{1} \rightarrow \mathrm{H}_{3}$ and $\mathrm{B}: \mathrm{H}_{2} \rightarrow \mathrm{H}_{3}$ are two bounded linear operators.

In order to solve the split equality feasibility problem (1.1), Moudafi and Al-Shemas [19], introduced the following simultaneous iterative method:

$$
\left\{\begin{array}{l}
x_{n+1}=P_{C}\left[x_{n}-\gamma A^{*}\left(A x_{n}-B y_{n}\right)\right] \\
y_{n+1}=P_{Q}\left[y_{n}+\gamma A^{*}\left(A x_{n}-B y_{n}\right)\right]
\end{array}\right.
$$

and under suitable conditions they proved the weak convergence of the sequence $\left(x_{n}, y_{n}\right)$ to a solution of (1.1) in Hilbert spaces.

Let $\mathrm{H}_{1}, \mathrm{H}_{2}$ be two real Hilbert spaces and $\mathrm{F}$ a real Banach space. $A: \mathrm{H}_{1} \rightarrow \mathrm{F}$ and $\mathrm{B}: \mathrm{H}_{2} \rightarrow \mathrm{F}$ are two bounded linear operators and $A^{*}$ and $B^{*}$ are the adjoint mappings of $A$ and $B$, respectively. For every $j=1,2, \cdots$, let $C_{j}$ and $Q_{j}$ be nonempty closed convex subsets of $H_{1}$ and $H_{2}$, respectively. $i_{C_{j}}$ and $i_{Q_{j}}$ denote the indicator functions of $C_{j}$ and $Q_{j}$, while $N_{C_{j}}(x)$ and $N_{Q_{j}}(y)$ are the normal cone of $C_{j}$ and $Q_{j}$ at $x$ and $y$, respectively, i.e.,

$$
\begin{aligned}
i_{C_{j}}(x) & = \begin{cases}0, & \text { if } x \in C_{j}, \\
+\infty, & \text { if } x \notin C_{j},\end{cases} & i_{Q_{j}}(y)= \begin{cases}0, & \text { if } y \in Q_{j}, \\
+\infty, & \text { if } y \notin Q_{j},\end{cases} \\
N_{C_{j}}(x) & =\left\{z \in H_{1}:\langle z, v-x\rangle \geqslant 0, \forall v \in C_{j}\right\}, & N_{Q_{j}}(y)=\left\{z \in H_{2}:\langle z, v-y\rangle \geqslant 0, \forall v \in Q_{j}\right\} .
\end{aligned}
$$

It is well-known that $i_{C_{j}}$ and $i_{Q_{j}}$ are proper convex and lower semicontinuous functions on $\mathrm{H}_{1}$ and $\mathrm{H}_{2}$, respectively. And the sub-differentials $\partial i_{C_{j}}$ and $\partial i_{Q_{j}}$ are maximal monotone operators. For $j=1,2, \cdots$ and for all $\mu>0$, we define the resolvent operator $J_{\mu}^{\partial i_{C_{j}}}$ of $\partial i_{C_{j}}$ by

$$
\mathrm{J}_{\mu}^{\partial i_{C_{j}}}(\cdot)=\left(\mathrm{I}+\mu \partial i_{C_{j}}\right)^{-1}(\cdot): \mathrm{H}_{1} \rightarrow \mathrm{H}_{1},
$$

where

$$
\begin{aligned}
\partial i_{C_{j}}(x)=\left\{z \in H_{1}: i_{C_{j}}(x)+\langle z, u-x\rangle \leqslant i_{C_{j}}(u), \forall u \in H_{1}\right\} & =\left\{z \in H_{1}:\langle z, u-x\rangle \leqslant 0, \forall u \in C_{j}\right\} \\
& =N_{C_{j}}(x), x \in C_{j} .
\end{aligned}
$$

Hence we have

$$
u=J_{\mu}^{\partial{ }^{i} C_{j}}(x) \Leftrightarrow x-u \in \mu N_{C_{j}}(u) \Leftrightarrow\langle x-u, y-u\rangle \leqslant 0, \forall y \in C_{j} \Leftrightarrow u=P_{C_{j}}(x) .
$$

Here $P_{C_{j}}$ is the metric projection from $H_{1}$ onto $C_{j}$. Therefore, we get

$$
\mathrm{J}_{\mu}^{\partial i_{C_{j}}}=\mathrm{P}_{\mathrm{C}_{j}} \text {, and } \mathrm{J}_{\mu}^{\partial i_{\mathrm{Q}_{j}}}=\mathrm{P}_{\mathrm{Q}_{j}}, j=1,2, \cdots,
$$

which implies

$$
\partial i_{C_{j}}{ }^{-1}(0)=F\left(J_{\mu}^{\partial i_{C_{j}}}\right)=F\left(P_{C_{j}}\right) \text {, and } \partial i_{Q_{j}}{ }^{-1}(0)=F\left(J_{\mu}^{\partial i_{Q_{j}}}\right)=F\left(P_{Q_{j}}\right), j=1,2, \cdots .
$$

The general split equality variational inclusion problem (GSEVIP) in a Banach space is defined as follows: find $(p, q) \in \mathrm{H}_{1} \times \mathrm{H}_{2}$, such that

$$
p \in \bigcap_{j=1}^{\infty} \partial i_{C_{j}}{ }^{-1}(0), \quad q \in \bigcap_{j=1}^{\infty} \partial i_{Q_{j}}{ }^{-1}(0), \quad \text { and } \quad A p=B q
$$


The set of all solutions of (GSEVIP) (1.3) is denoted by $\Omega$, i.e,

$$
\Omega=\left\{(p, q) \in \mathrm{H}_{1} \times \mathrm{H}_{2}: \mathrm{p} \in \bigcap_{j=1}^{\infty} \partial i_{\mathrm{C}_{j}}{ }^{-1}(0), \mathrm{q} \in \bigcap_{j=1}^{\infty} \partial i_{\mathrm{Q}_{j}}{ }^{-1}(0), \text { and } A \mathrm{p}=\mathrm{Bq}\right\} .
$$

In this paper, we introduce a new iterative algorithm for solving the general split equality variational inclusion problem (GSEVIP) (1.3) in a Banach space and show that the suggested the iteration algorithm converges strongly to a solution of (GSEVIP) (1.3). The results of this paper extend and improve the corresponding results announced by Chang et al. [8, 9], and Moudafi and Al-Shemas [19].

\section{Preliminaries and lemmas}

In this section, we give some definitions and preliminaries which will be used in the sequel. Let $\mathrm{H}$ be a real Hilbert space and $\mathrm{C}$ be a nonempty closed convex subset of $\mathrm{H}$.

An operator $\mathrm{G}: \mathrm{H} \rightarrow \mathrm{H}$ is said to be

(i) a nonexpansive mapping, if

$$
\|G x-G y\| \leqslant\|x-y\|, \forall x, y \in H ;
$$

(ii) a firmly nonexpansive mapping, if

$$
\|G x-G y\|^{2} \leqslant\langle G x-G y, x-y\rangle, \forall x, y \in H .
$$

We denote by $\mathrm{P}_{\mathrm{C}}$ the Metric projection from $\mathrm{H}$ onto $\mathrm{C}$. Obviously, $\mathrm{P}_{\mathrm{C}}$ is a firmly nonexpansive mapping from $\mathrm{H}$ onto $\mathrm{C}$. Further, for any $x \in \mathrm{H}, \mathrm{z}=\mathrm{P}_{\mathrm{C}} x$ if and only if $\langle x-z, z-y\rangle \geqslant 0$, for all $\mathrm{y} \in \mathrm{C}$.

Let $\mathrm{F}$ be a real smooth Banach space. $\mathrm{J}_{\mathrm{F}}$ is the dual mapping of $\mathrm{F}$ defined by

$$
\mathrm{J}_{\mathrm{F}}(\mathrm{x})=\left\{\mathrm{x}^{*} \in \mathrm{F}^{*}:\left\langle x, x^{*}\right\rangle=\|x\|^{2}=\left\|x^{*}\right\|^{2}, x \in \mathrm{F}\right\} .
$$

Lemma 2.1 ([6]). Let $\mathrm{H}$ be a real Hilbert space. Then for all $\mathrm{x}, \mathrm{y} \in \mathrm{H}$, we have

$$
\|x+y\|^{2} \leqslant\|x\|^{2}+2\langle y, x+y\rangle .
$$

Lemma 2.2 ([13]). Let $\left\{a_{n}\right\},\left\{b_{n}\right\}$, and $\left\{c_{n}\right\}$ be sequences of positive real numbers satisfying $a_{n} \leqslant\left(1-b_{n}\right) a_{n}+c_{n}$ for all $\mathrm{n} \geqslant 1$. If the following conditions are satisfied

(1) $b_{n} \in[0,1]$ and $\sum_{n=1}^{\infty} b_{n}=\infty$;

(2) $\sum_{n=1}^{\infty} c_{n}<\infty$, or $\limsup _{n \rightarrow \infty} \frac{c_{n}}{b_{n}} \leqslant 0$,

then $\lim _{n \rightarrow \infty} a_{n}=0$.

Lemma 2.3 ([10]). Let $\mathrm{H}$ be a real Hilbert space, $\mathrm{B}: \mathrm{H} \rightarrow 2^{\mathrm{H}}$ be a maximal monotone mapping and $\mathrm{J}_{\beta}^{\mathrm{B}}$ be the resolvent mapping of $B$ defined by $\mathrm{J}_{\beta}^{\mathrm{B}}=(\mathrm{I}+\beta \mathrm{B})^{-1}, \beta>0$, then

(1) for each $\beta>0, \mathrm{~J}_{\beta}^{\mathrm{B}}$ is a single-valued and firmly nonexpansive mapping;

(2) $\mathrm{D}\left(\mathrm{J}_{\beta}^{\mathrm{B}}\right)=\mathrm{H}$ and $\mathrm{F}\left(\mathrm{J}_{\beta}^{\mathrm{B}}\right)=\mathrm{B}^{-1}(0)$;

(3) $\left(\mathrm{I}-\mathrm{J}_{\beta}^{\mathrm{B}}\right)$ is a firmly nonexpansive mapping for each $\beta>0$;

(4) suppose that $\mathrm{B}^{-1}(0) \neq \emptyset$, then

$$
\left\|x-\mathrm{J}_{\beta}^{\mathrm{B}} x\right\|^{2}+\left\|\mathrm{J}_{\beta}^{\mathrm{B}} x-x^{*}\right\| \leqslant\left\|x-x^{*}\right\|^{2}
$$

for each $x \in \mathrm{H}$, each $x^{*} \in \mathrm{B}^{-1}(0)$, and each $\beta>0$;

(5) suppose that $\mathrm{B}^{-1}(0) \neq \emptyset$, then $\left\langle x-\mathrm{J}_{\beta}^{\mathrm{B}} \mathrm{x}, \mathrm{J}_{\beta}^{\mathrm{B}} \mathrm{x}-w\right\rangle \geqslant 0$ for each $\mathrm{x} \in \mathrm{H}$, each $w \in \mathrm{B}^{-1}(0)$, and each $\beta>0$. 
Lemma 2.4 ([7]). Let $\mathrm{H}$ be a real Hilbert space and $\left\{x_{n}\right\}$ be a sequence in $\mathrm{H}$. Then for any sequence $\left\{\lambda_{n}\right\}\left(\lambda_{n} \in\right.$ $(0,1)$ with $\sum_{n=1}^{\infty} \lambda_{n}=1$, the following inequality holds

$$
\left\|\sum_{n=1}^{\infty} \lambda_{n} x_{n}\right\|^{2} \leqslant \sum_{n=1}^{\infty} \lambda_{n}\left\|x_{n}\right\|^{2}-\lambda_{i} \lambda_{j}\left\|x_{i}-x_{j}\right\|^{2}, \forall i, j, i<j .
$$

Lemma 2.5 ([18]). Let $\left\{\mathrm{t}_{\mathrm{n}}\right\}$ be a sequence of real numbers. If there exists a subsequence $\left\{\mathrm{n}_{\mathfrak{i}}\right\}$ of $\{\mathrm{n}\}$, such that $t_{n_{i}}<t_{n_{i}+1}$ for all $i \geqslant 1$, then there exists a nondecreasing sequence $\{\theta(n)\}$ with $\theta(n) \rightarrow \infty$ as $n \rightarrow \infty$, such that for all (sufficiently large) positive integer number $\mathrm{n}$, the following holds:

$$
t_{\theta(n)} \leqslant t_{\theta(n)+1}, t_{n} \leqslant t_{\theta(n)+1} .
$$

In fact,

$$
\theta(n)=\max \left\{k \leqslant n: t_{k} \leqslant t_{k+1}\right\} .
$$

Lemma 2.6 (demiclosedness principle). Let $\mathrm{C}$ be a nonempty closed convex subset of a real Hilbert space $\mathrm{H}$ and $\mathrm{T}: \mathrm{C} \rightarrow \mathrm{C}$ be a nonexpansive mapping with $\operatorname{Fix}(\mathrm{T}) \neq \emptyset$. Then $\mathrm{I}-\mathrm{T}$ is said to be demi-closed at zero, if for any sequence $\left\{x_{n}\right\} \subset C$ with $x_{n} \rightarrow x$ and $\left\|x_{n}-T x_{n}\right\| \rightarrow 0$, then $x=T x$.

\section{The main results}

In this section, we show some strong convergence theorems for finding a common element of the solution set of the general split equality variational inclusion problem (GSEVIP) (1.3) in a Banach space.

In order to solve problem (GSEVIP) (1.3), we propose the following simultaneous type iterative algorithm.

Algorithm 3.1. For any given $W_{0}=\left(x_{0}, y_{0}\right), V_{0}=\left(v_{01}, v_{02}\right) \in H_{1} \times H_{2}$, the iterative sequence $\left\{W_{n}\right\} \subset$ $\mathrm{H}_{1} \times \mathrm{H}_{2}$ is generated by

$$
W_{n+1}=\alpha_{n} W_{n}+\beta_{n} V_{0}+\sum_{j=1}^{\infty} \gamma_{n, j} J_{\mu}^{\left(\partial i_{C_{j}}, \partial i_{Q_{j}}\right)}\left(I-\mu G^{*} J_{F} G\right) W_{n}, \quad n \geqslant 0,
$$

where $\left\{\alpha_{n}\right\},\left\{\beta_{n}\right\},\left\{\gamma_{n, j}\right\}$ are the sequences of nonnegative numbers satisfying

$$
\begin{aligned}
\alpha_{n}+\beta_{n}+\sum_{j=1}^{\infty} \gamma_{n, j} & =1, \quad n \geqslant 0, \\
J_{\mu}\left(\partial i_{C_{j}}, \partial i_{Q_{j}}\right) & =\left(\begin{array}{c}
J_{\mu}^{\partial i_{C_{j}}} \\
\partial i_{Q_{j}}
\end{array}\right), G=\left(\begin{array}{ll}
A & -B
\end{array}\right), G^{*}=\left(\begin{array}{c}
A^{*} \\
-B^{*}
\end{array}\right), G^{*} J_{F} G=\left(\begin{array}{cc}
A^{*} J_{F} A & -A^{*} J_{F} B \\
-B^{*} J_{F} A & B^{*} J_{F} B
\end{array}\right) .
\end{aligned}
$$

We also need the following conclusion.

Lemma 3.2. If the set of solutions of (GSEVIP) (1.3) is $\Omega \neq \emptyset$, then $\mathrm{W}^{*}=\left(x^{*}, y^{*}\right) \in \mathrm{H}_{1} \times \mathrm{H}_{2}$ is a solution of (GSEVIP) (1.3) if and only if for each $j \geqslant 1$, and for any given $\mu>0$

$$
W^{*}=J_{\mu}^{\left(\partial i_{C_{j}}, \partial i Q_{j}\right)}\left(I-\mu G^{*} J_{F} G\right) W^{*} .
$$

Proof. Indeed, $W^{*}=\left(x^{*}, y^{*}\right) \in \mathrm{H}_{1} \times \mathrm{H}_{2}$ is a solution of (GSEVIP) (1.3), from Lemma 2.3 (2), for all $j \geqslant 1$, we have

$$
x^{*} \in \partial i_{C_{j}}{ }^{-1}(0)=F\left(J_{\mu}^{\partial i_{C_{j}}}\right), y^{*} \in \partial i_{Q_{j}}{ }^{-1}(0)=F\left(J_{\mu}^{\partial i_{Q_{j}}}\right), A x^{*}=B y^{*}, G W^{*}=A x^{*}-B y^{*}=0 .
$$


Thus for any $\mu>0$,

$$
J_{\mu}^{\left(\partial i_{C_{j}}, \partial i_{Q_{j}}\right)}\left(I-\mu G^{*} J_{F} G\right) W^{*}=J_{\mu}^{\left(\partial i_{C_{j}}, \partial i_{Q_{j}}\right)} W^{*}=\left(J_{\mu}^{\partial i_{C_{j}}} \chi^{*}, J_{\mu} J_{Q_{Q_{j}}} y^{*}\right)=\left(x^{*}, y^{*}\right)=W^{*} .
$$

Conversely, if $W^{*}=\left(x^{*}, y^{*}\right) \in H_{1} \times H_{2}$ satisfies (3.2), we have

$$
\left\{\begin{array}{l}
x^{*}=J_{\mu}^{\partial i_{C_{j}}}\left(x^{*}-\mu A^{*} J_{F}\left(A x^{*}-B y^{*}\right)\right) \\
y^{*}=J_{\mu}^{\partial i_{Q_{j}}}\left(y^{*}+\mu B^{*} J_{F}\left(A x^{*}-B y^{*}\right)\right)
\end{array}\right.
$$

From Lemma 2.3 (5) and $\Omega \neq \emptyset$, we have

$$
\left\langle x^{*}-\left(x^{*}-\mu A^{*} J_{F}\left(A x^{*}-B y^{*}\right)\right), x-x^{*}\right\rangle \geqslant 0, \quad \forall x \in \partial i_{C_{j}}{ }^{-1}(0) .
$$

Since $\mu>0$, we get

$$
\left\langle\mathrm{J}_{\mathrm{F}}\left(A x^{*}-B y^{*}\right), A x-A x^{*}\right\rangle \geqslant 0, \quad \forall x \in \partial i_{Q_{j}}{ }^{-1}(0) .
$$

Simplifying, from (3.3) and Lemma 2.3 (1), we have

$$
\left\langle J_{F}\left(A x^{*}-B y^{*}\right), B y^{*}-B y\right\rangle \geqslant 0, \quad \forall y \in \partial i_{Q_{j}}{ }^{-1}(0) .
$$

Adding up (3.4) and (3.5), we get

$$
\left\langle J_{F}\left(A x^{*}-B y^{*}\right), A x^{*}-B y^{*}\right\rangle \leqslant\left\langle J_{F}\left(A x^{*}-B y^{*}\right), A x-B y\right\rangle \forall x \in \partial i_{C_{j}}{ }^{-1}(0), \forall y \in \partial i_{Q_{j}}{ }^{-1}(0) .
$$

So, we get

$$
\left\|A x^{*}-B y^{*}\right\|^{2} \leqslant\left\langle J_{F}\left(A x^{*}-B y^{*}\right), A x-B y\right\rangle, \quad \forall x \in \partial i_{C_{j}}{ }^{-1}(0), \forall y \in \partial i_{Q_{j}}{ }^{-1}(0) .
$$

Since the set of solutions of (GSEVIP) (1.3) is $\Omega \neq \emptyset$, taking $W=\left(x_{0}, y_{0}\right) \in \Omega$ and $x=x_{0}, y=y_{0}$, we get

$$
\left\|A x^{*}-B y^{*}\right\|=0 \text {, i.e., } A x^{*}=B y^{*} .
$$

From (3.3), we have

$$
\left\{\begin{array}{l}
x^{*}=J_{\mu}^{\partial i_{C_{j}}} x^{*}, \\
y^{*}=J_{\mu}^{\partial i_{Q_{j}}} y^{*},
\end{array} \quad \text { i.e., } x^{*} \in F\left(J_{\mu}^{\partial i_{C_{j}}}\right)=\partial i_{C_{j}}{ }^{-1}(0), y^{*} \in F\left(J_{\mu}^{\partial i_{Q_{j}}}\right)=\partial i_{Q_{j}}{ }^{-1}(0), \forall j \geqslant 1,\right.
$$

which from (3.6) and (3.7) implies that $W^{*} \in \Omega$.

Lemma 3.3. If $\mu \in\left(0, \frac{2}{\mathrm{~L}}\right)$, where $\mathrm{L}=\|\mathrm{G}\|^{2}$, then $\mathrm{I}-\mu \mathrm{G}^{*} \mathrm{~J}_{\mathrm{F}} \mathrm{G}: \mathrm{H}_{1} \times \mathrm{H}_{2} \rightarrow \mathrm{H}_{1} \times \mathrm{H}_{2}$ is a nonexpansive mapping. Proof. For any given $w, u \in \mathrm{H}_{1} \times \mathrm{H}_{2}$, we have

$$
\begin{aligned}
\left\|\left(I-\mu G^{*} J_{F} G\right) u-\left(I-\lambda G^{*} J_{F} G\right) w\right\|^{2} & =\left\|(u-w)-\mu G^{*} J_{F} G(u-w)\right\|^{2} \\
& =\|u-w\|^{2}+\mu^{2}\left\|G^{*} J_{F} G(u-w)\right\|^{2}-2 \mu\left\langle u-w, G^{*} J_{F} G(u-w)\right\rangle \\
& \leqslant\|u-w\|^{2}+\mu^{2} L\left\|J_{F} G(u-w)\right\|^{2}-2 \mu\left\langle G(u-w), J_{F} G(u-w)\right\rangle . \\
& =\|u-w\|^{2}+\mu^{2} L\|G(u-w)\|^{2}-2 \mu\|G(u-w)\|^{2} . \\
& =\|u-w\|^{2}-\mu(2-\mu L)\|G(u-w)\|^{2} . \\
& \leqslant\|u-w\|^{2} .
\end{aligned}
$$

This completes the proof. 
Theorem 3.4. Let $\left\{W_{n}\right\}$ be the sequence defined by (3.1). If the set of solutions of (GSEVIP) (1.3) is $\Omega \neq \emptyset$ and the following conditions are satisfied:

(B1) $\left\{\alpha_{n}\right\},\left\{\beta_{n}\right\},\left\{\gamma_{n, j}\right\} \subset[0,1]$, for any $n \geqslant 0, \alpha_{n}+\beta_{n}+\sum_{j=1}^{\infty} \gamma_{n, j}=1$;

(B2) $\sum_{n=0}^{\infty} \beta_{n}=\infty$ and $\lim _{n \rightarrow \infty} \beta_{n}=0$;

(B3) $\mu \in\left(0, \frac{2}{\mathrm{~L}}\right)$, where $\mathrm{L}=\|\mathrm{G}\|^{2}$;

(B4) $\liminf _{n \rightarrow \infty} a_{n} \gamma_{n, j}>0, \forall j \geqslant 1$,

then the sequence $\left\{\mathrm{W}_{\mathrm{n}}\right\}$ converges strongly to $\mathrm{W}^{*}=\mathrm{P}_{\Omega} \mathrm{V}_{0}$, which is a solution of (GSEVIP) (1.3).

Proof. We shall divide the proof into three steps.

Step (I). Showing that $\left\{W_{n}\right\}$ is bounded.

For any $p \in \Omega$, from Lemma 3.2, we have

$$
p=J_{\mu}^{\left(\partial i_{C_{j}}, \partial i_{Q_{j}}\right)}\left(I-\mu G^{*} J_{F} G\right) p .
$$

Form Lemma 3.3, Lemma 2.3 (1), and condition (B3), we get

$$
\begin{aligned}
& \left\|\mathrm{W}_{\mathrm{n}+1}-\mathrm{p}\right\| \\
& =\left\|\alpha_{n} W_{n}+\beta_{n} V_{0}+\sum_{j=1}^{\infty} \gamma_{n, j} J_{\mu}^{\left(\partial i_{C_{j}}, \partial i_{Q_{j}}\right)}\left(I-\mu G^{*} J_{F} G\right) W_{n}-p\right\| \\
& \leqslant \alpha_{n}\left\|W_{n}-p\right\|+\beta_{n}\left\|V_{0}-p\right\|+\sum_{j=1}^{\infty} \gamma_{n, j}\left\|J_{\mu}^{\left(\partial i_{c_{j}}, \partial i_{Q_{j}}\right)}\left(I-\mu G^{*} J_{F} G\right) W_{n}-p\right\| \\
& \leqslant \alpha_{n}\left\|W_{n}-p\right\|+\beta_{n}\left\|V_{0}-p\right\|+\sum_{j=1}^{\infty} \gamma_{n, j}\left\|\left(I-\mu G^{*} J_{F} G\right) W_{n}-p\right\| \\
& \leqslant \alpha_{n}\left\|W_{n}-p\right\|+\beta_{n}\left\|V_{0}-p\right\|+\sum_{j=1}^{\infty} \gamma_{n, j}\left\|W_{n}-p\right\| \\
& =\left(1-\beta_{n}\right)\left\|W_{n}-p\right\|+\beta_{n}\left\|V_{0}-p\right\| \\
& \leqslant \max \left\{\left\|W_{n}-p\right\|,\left\|V_{0}-p\right\|\right\} \text {. }
\end{aligned}
$$

By induction, we have

$$
\left\|W_{n}-p\right\| \leqslant \max \left\{\left\|W_{0}-p\right\|,\left\|V_{0}-p\right\|\right\}, \quad \forall n \geqslant 0,
$$

which implies that $\left\{W_{n}\right\}$ is bounded.

Step (II). We show that the following inequality holds

$$
\alpha_{n} \gamma_{n, j}\left\|W_{n}-J_{\mu}^{\left(\partial i_{C_{j}}, \partial i_{Q_{j}}\right)}\left(I-\mu G^{*} J_{F} G\right) W_{n}\right\|^{2} \leqslant\left\|W_{n}-p\right\|^{2}-\left\|W_{n+1}-p\right\|^{2}+\beta_{n}\left\|V_{0}-p\right\|^{2} .
$$

From Lemma 2.4 and (3.1), we have

$$
\begin{aligned}
& \left\|W_{n+1}-p\right\|^{2}=\left\|\alpha_{n} W_{n}+\beta_{n} V_{0}+\sum_{j=1}^{\infty} \gamma_{n, j} J_{\mu}^{\left(\partial i_{C_{j}}, \partial i_{Q_{j}}\right)}\left(I-\mu G^{*} J_{F} G\right) W_{n}-p\right\|^{2} \\
& =\left\|\alpha_{n}\left(W_{n}-p\right)+\beta_{n}\left(V_{0}-p\right)+\sum_{j=1}^{\infty} \gamma_{n, j}\left(J_{\mu}^{\left(\partial i_{C_{j}}, \partial i_{Q_{j}}\right)}\left(I-\mu G^{*} J_{F} G\right) W_{n}-p\right)\right\|^{2} \\
& \leqslant \alpha_{n}\left\|W_{n}-p\right\|^{2}+\beta_{n}\left\|V_{0}-p\right\|^{2}+\sum_{j=1}^{\infty} \gamma_{n, j}\left\|J_{\mu}^{\left(\partial i_{c_{j}}, \partial i_{Q_{j}}\right)}\left(I-\mu G^{*} J_{F} G\right) W_{n}-p\right\|^{2} \\
& -\alpha_{n} \gamma_{n, j}\left\|W_{n}-J_{\mu}^{\left(\partial i_{C_{j}}, \partial i_{Q_{j}}\right)}\left(I-\mu G^{*} J_{F} G\right) W_{n}\right\|^{2} \\
& \leqslant \alpha_{n}\left\|W_{n}-p\right\|^{2}+\beta_{n}\left\|V_{0}-p\right\|^{2}+\sum_{j=1}^{\infty} \gamma_{n, j}\left\|\left(I-\mu G^{*} J_{F} G\right) W_{n}-p\right\|^{2} \\
& -\alpha_{n} \gamma_{n, j}\left\|W_{n}-J_{\mu}^{\left(\partial i_{C_{j}}, \partial i_{Q_{j}}\right)}\left(I-\mu G^{*} J_{F} G\right) W_{n}\right\|^{2}
\end{aligned}
$$




$$
\begin{aligned}
\leqslant & \alpha_{n}\left\|W_{n}-p\right\|^{2}+\beta_{n}\left\|V_{0}-p\right\|^{2}+\sum_{j=1}^{\infty} \gamma_{n, j}\left\|W_{n}-p\right\|^{2} \\
& -\alpha_{n} \gamma_{n, j}\left\|W_{n}-J_{\mu}^{\left(\partial i_{C_{j}}, \partial i_{Q_{j}}\right)}\left(I-\mu G^{*} J_{F} G\right) W_{n}\right\|^{2} \\
\leqslant & \left(1-\beta_{n}\right)\left\|W_{n}-p\right\|^{2}+\beta_{n}\left\|V_{0}-p\right\|^{2}-\alpha_{n} \gamma_{n, j}\left\|W_{n}-J_{\mu}^{\left(\partial i_{C_{j}}, \partial i_{Q_{j}}\right)}\left(I-\mu G^{*} J_{F} G\right) W_{n}\right\|^{2} \\
\leqslant & \left\|W_{n}-p\right\|^{2}+\beta_{n}\left\|V_{0}-p\right\|^{2}-\alpha_{n} \gamma_{n, j}\left\|W_{n}-J_{\mu}^{\left(\partial i_{C_{j}}, \partial i_{Q_{j}}\right)}\left(I-\mu G^{*} J_{F} G\right) W_{n}\right\|^{2} .
\end{aligned}
$$

Inequality (3.9) is proved.

Step (III). Since the set of solutions of (GSEVIP) (1.3) is $\Omega \neq \emptyset$ and $C_{j}$ and $Q_{j}(j=1,2, \cdots)$ are nonempty closed convex subsets of $\mathrm{H}_{1}$ and $\mathrm{H}_{2}$, respectively, from (1.2) and lemma 2.3, we can get the set of solutions of (GSEVIP) (1.3), $\Omega$, is nonempty closed convex. Setting $W^{*}=P_{\Omega} V_{0}$, we have $W^{*} \in \Omega$. We will prove that $\left\{W_{n}\right\}$ converges strongly to $W^{*}$.

We consider two cases: (I) Suppose that the sequence $\left\{\left\|W_{n}-W^{*}\right\|\right\}$ is monotone.

Since $\left\{\left\|W_{n}-W^{*}\right\|\right\}$ is monotone, following Step (I), it is obvious that $\left\{\left\|W_{n}-W^{*}\right\|\right\}$ is convergent. From conditions (B2), (B4), and (3.9), we have

$$
\lim _{n \rightarrow \infty}\left\|W_{n}-J_{\mu}^{\left(\partial i_{C_{j}}, \partial i_{Q_{j}}\right)}\left(I-\mu G^{*} J_{F} G\right) W_{n}\right\|=0,
$$

and

$$
\begin{aligned}
\left\|W_{n+1}-W^{*}\right\|^{2}= & \left\|\alpha_{n} W_{n}+\beta_{n} V_{0}+\sum_{j=1}^{\infty} \gamma_{n, j} J_{\mu}^{\left(\partial i_{C_{j}}, \partial i_{Q_{j}}\right)}\left(I-\mu G^{*} J_{F} G\right) W_{n}-W^{*}\right\|^{2} \\
= & \left\|\alpha_{n}\left(W_{n}-W^{*}\right)+\beta_{n}\left(V_{0}-W^{*}\right)+\sum_{j=1}^{\infty} \gamma_{n, j}\left(J_{\mu}^{\left(\partial i_{c_{j}}, \partial i_{Q_{j}}\right)}\left(I-\mu G^{*} J_{F} G\right) W_{n}-W^{*}\right)\right\|^{2} \\
\leqslant & \left\|\alpha_{n}\left(W_{n}-W^{*}\right)+\sum_{j=1}^{\infty} \gamma_{n, j}\left(J_{\mu}^{\left(\partial i_{C_{j}}, \partial i_{Q_{j}}\right)}\left(I-\mu G^{*} J_{F} G\right) W_{n}-W^{*}\right)\right\|^{2} \\
& +2 \beta_{n}\left\langle V_{0}-W^{*}, W_{n+1}-W^{*}\right\rangle \quad(b y \text { Lemma } 2.1) \\
\leqslant & \left\{\alpha_{n}\left\|W_{n}-W^{*}\right\|+\sum_{j=1}^{\infty} \gamma_{n, j}\left\|W_{n}-W^{*}\right\|\right\}^{2}+2 \beta_{n}\left\langle V_{0}-W^{*}, W_{n+1}-W^{*}\right\rangle \\
= & \left(1-\beta_{n}\right)^{2}\left\|W_{n}-W^{*}\right\|^{2}+2 \beta_{n}\left\langle V_{0}-W^{*}, W_{n+1}-W^{*}\right\rangle .
\end{aligned}
$$

Since $\beta_{n} \in[0,1]$. Then we have

$$
\left\|W_{n+1}-W^{*}\right\|^{2} \leqslant\left(1-\beta_{n}\right)\left\|W_{n}-W^{*}\right\|^{2}+2 \beta_{n}\left\langle V_{0}-W^{*}, W_{n+1}-W^{*}\right\rangle .
$$

Since $\left\{W_{n}\right\}$ is bounded, there exists a subsequence $\left\{W_{n_{k}}\right\} \subset\left\{W_{n}\right\}$ such that $W_{n_{k}} \rightarrow W \in H_{1} \times H_{2}$. From (3.10), we get

$$
\lim _{n \rightarrow \infty}\left\|W_{n_{k}}-J_{\mu}^{\left(\partial i_{c_{j}}, \partial i_{Q_{j}}\right)}\left(I-\mu G^{*} J_{F} G\right) W_{n_{k}}\right\|=0 .
$$

Since $J_{\mu}^{\left(\partial i_{C_{j}}, \partial i_{Q_{j}}\right)}\left(I-\mu G^{*} J_{F} G\right)$ is a nonexpansive mapping, by Lemma 2.6, we have

$$
W=J_{\mu}^{\left(\partial i_{C_{j}}, \partial i_{Q_{j}}\right)}\left(I-\mu G^{*} J_{F} G\right) W .
$$

From Lemma 3.2, this shows that $W \in \Omega$. We get

$$
\limsup _{n \rightarrow \infty}\left\langle V_{0}-W^{*}, W_{n}-W^{*}\right\rangle=\lim _{k \rightarrow \infty}\left\langle V_{0}-W^{*}, W_{n_{k}}-W^{*}\right\rangle \leqslant\left\langle V_{0}-W^{*}, W-W^{*}\right\rangle \leqslant 0
$$


Taking $a_{n}=\left\|W_{n}-W^{*}\right\|, b_{n}=\beta_{n}$, and $c_{n}=\beta_{n}\left\langle V_{0}-W^{*}, W_{n+1}-W^{*}\right\rangle$, all conditions of Lemma 2.2 are satisfied, so $\lim _{n \rightarrow \infty}\left\|W_{n+1}-W^{*}\right\|=0$.

(II) Suppose that the sequence $\left\{\left\|W_{n}-W^{*}\right\|\right\}$ is not monotone.

By Lemma 2.5, there exists a sequence of positive integers, $\{\theta(n)\}, n \geqslant n_{0}$ (where $n_{0}$ is large enough) such that

$$
\theta(n)=\max \left\{k \leqslant n:\left\|W_{k}-W^{*}\right\| \leqslant\left\|W_{k+1}-W^{*}\right\|\right\} .
$$

Clearly, $\{\theta(n)\}$ is nondecreasing and $\theta(n) \rightarrow \infty$ as $n \rightarrow \infty$ and for all $n \geqslant n_{0}$,

$$
\left\|W_{\theta(n)}-W^{*}\right\| \leqslant\left\|W_{\theta(n)+1}-W^{*}\right\|, \quad\left\|W_{n}-W^{*}\right\| \leqslant\left\|W_{\theta(n)+1}-W^{*}\right\| .
$$

Hence, $\left\{\left\|W_{\theta(n)}-W^{*}\right\|\right\}$ is a nondecreasing sequence. By virtue of Case $(I), \lim _{n \rightarrow \infty}\left\|W_{\theta(n)}-W^{*}\right\|=0$ and $\lim _{n \rightarrow \infty}\left\|W_{\theta(n)+1}-W^{*}\right\|=0$, we have

$$
0 \leqslant\left\|W_{n}-W^{*}\right\| \leqslant \max \left\{\left\|W_{n}-W^{*}\right\|,\left\|W_{\theta(n)}-W^{*}\right\|\right\} \leqslant\left\|W_{\theta(n)+1}-W^{*}\right\| \rightarrow 0, \text { as } n \rightarrow \infty .
$$

This implies that $W_{n} \rightarrow W^{*}$ and $W^{*}=P_{\Omega} V_{0}$ is a solution of (GSEVIP) (1.3).

\section{Applications}

In this section, two examples will be illustrated to verify the validity of the proposed algorithm in Section 3.

\subsection{Application to the general split equality equilibrium problem in Banach space}

Let $\mathrm{H}_{1}, \mathrm{H}_{2}$ be two real Hilbert spaces and $\mathrm{F}$ is a real smooth Banach space. Let $\mathrm{C}_{1}$ and $\mathrm{C}_{2}$ are nonempty closed convex subsets of $\mathrm{H}_{1}$ and $\mathrm{H}_{2}$, respectively, and $A: \mathrm{H}_{1} \rightarrow \mathrm{F}, \mathrm{B}: \mathrm{H}_{2} \rightarrow \mathrm{F}$ are bounded linear operator. let $F_{i}: C_{1} \times C_{1} \rightarrow R$ and $G_{i}: C_{2} \times C_{2} \rightarrow R, i=1,2, \cdots$ be two equilibrium functions, where $C$ and $Q$ are nonempty closed convex subsets of $\mathrm{H}_{1}$ and $\mathrm{H}_{2}$, respectively.

Assumption 4.1. Let $\mathrm{F}: \mathrm{C} \times \mathrm{C} \rightarrow \mathrm{R}$ be an equilibrium function satisfying the following assumptions:

(1) $\mathrm{F}(\mathrm{x}, \mathrm{x})=0, \forall x \in \mathrm{C}$;

(2) $F$ is monotone, i.e., $F(x, y)+F(y, x) \leqslant 0, \quad \forall x, y \in C$;

(3) for each $x, y, z \in C$, $\limsup F(t z+(1-t) x, y) \leqslant F(x, y)$;

(4) for each $x \in C, y \longmapsto F(x, y)$ is convex and lower semi-continuous.

For Assumption 4.1, see [1, 21].

Lemma 4.2 ([11]). Let $C$ be a nonempty closed convex subset of a Hilbert space $\mathrm{H}$ and $\mathrm{F}: \mathrm{C} \times \mathrm{C} \rightarrow \mathrm{R}$ be a equilibrium which satisfies Assumption 4.1. For all $\mathrm{r}>0$ and $\mathrm{x} \in \mathrm{H}$, the resolvent of the equilibrium function $\mathrm{F}$ is the operator $\mathrm{T}_{\mathrm{r}}^{\mathrm{F}}: \mathrm{H} \rightarrow \mathrm{C}$ defined by

$$
\mathrm{T}_{\mathrm{r}}^{\mathrm{F}}(\mathrm{x})=\left\{z \in \mathrm{C}: \mathrm{F}(z, y)+\frac{1}{\mathrm{r}}\langle y-z, z-x\rangle \geqslant 0, \forall y \in C\right\} .
$$

Then $\mathrm{T}_{\mathrm{r}}^{\mathrm{F}}$ is well-defined and the followings hold:

(1) $T_{r}^{F}$ is nonempty and single-valued;

(2) $\mathrm{T}_{\mathrm{r}}^{\mathrm{F}}$ is firmly nonexpansive, i.e., for any $x, y \in \mathrm{H}_{1}$

$$
\left\|T_{r}^{F}(x)-T_{r}^{F}(y)\right\|^{2} \leqslant\left\langle T_{r}^{F}(x)-T_{r}^{F}(y), x-y\right\rangle ;
$$

(3) $F\left(\mathrm{~T}_{\mathrm{r}}^{\mathrm{F}}\right)=E P(\mathrm{~F})$;

(4) $E P(\mathrm{~F})$ is closed and convex. 
Let $\mathrm{H}_{1}, \mathrm{H}_{2}$ be two real Hilbert spaces. Let $\mathrm{C}_{1}$ and $\mathrm{C}_{2}$ be nonempty closed convex subsets of $\mathrm{H}_{1}$ and $\mathrm{H}_{2}$, respectively. The general split equality equilibrium problem (GSEEP) is defined as follows: to find $x^{*} \in C_{1}, y^{*} \in C_{2}$, such that

$$
F_{i}\left(x^{*}, x\right) \geqslant 0, \forall x \in C_{1}, G_{i}\left(y^{*}, y\right) \geqslant 0, \forall y \in C_{2} \text { and } A x^{*}=B y^{*} .
$$

We know that the general split equality equilibrium problem (GSEEP) (4.1) is equivalent to find $x^{*} \in$ $\mathrm{C}_{1}, \mathrm{y}^{*} \in \mathrm{C}_{2}$, such that for each $\lambda>0$,

$$
x^{*} \in \bigcap_{i=1}^{\infty} E P\left(F_{i}, C_{1}\right)=\bigcap_{i=1}^{\infty} F\left(T_{r}^{F_{i}}\right), y^{*} \in \bigcap_{i=1}^{\infty} E P\left(G_{i}, C_{2}\right)=\bigcap_{i=1}^{\infty} F\left(T_{r}^{G_{i}}\right) \text {, such that } A x^{*}=B y^{*}
$$

Letting $C=\bigcap_{i=1}^{\infty} F\left(T_{r}^{F_{i}}\right), Q=\bigcap_{i=1}^{\infty} F\left(T_{r}^{G_{i}}\right)$, by Lemma 4.2, C (resp.Q) is a nonempty closed and convex subset of $C$ (res.Q).

The general split equality equilibrium problem (GSEEP) in Banach space is defined as follows:

$$
p \in C, q \in Q \text {, such that } A p=B q .
$$
rithm.

In order to solve problem (GSEEP) (4.2), we propose the following simultaneous type iterative algoAlgorithm 4.3. For any given $W_{0}=\left(x_{0}, y_{0}\right), v_{0}=\left(v_{01}, v_{02}\right) \in H_{1} \times H_{2}$, the iterative sequence $W_{n} \in H_{1} \times H_{2}$ is generated by

$$
W_{n+1}=\alpha_{n} W_{n}+\beta_{n} V_{0}+P_{C \times Q}\left(I-\mu_{n} G^{*} J_{F} G\right) W_{n} \quad n \geqslant 0,
$$

where $\left\{\alpha_{n}\right\},\left\{\beta_{n}\right\},\left\{\gamma_{n, j}\right\}$ are the sequences in $[0,1]$ with $\alpha_{n}+\beta_{n}+\gamma_{n}=1$, for all $n \geqslant 0$,

$$
P_{C \times Q}=\left(\begin{array}{c}
P_{C} \\
P_{Q}
\end{array}\right), G=\left(\begin{array}{cc}
A & -B
\end{array}\right), G^{*}=\left(\begin{array}{c}
A^{*} \\
-B^{*}
\end{array}\right), G^{*} J_{F} G=\left(\begin{array}{cc}
A^{*} J_{F} A & -A^{*} J_{F} B \\
-B^{*} J_{F} A & B^{*} J_{F} B
\end{array}\right) .
$$

Theorem 4.4. Let $\mathrm{H}_{1}, \mathrm{H}_{2}, \mathrm{~F}, \mathrm{C}, \mathrm{Q}, \mathrm{A}, \mathrm{B}, \mathrm{A}^{*}, \mathrm{~B}^{*}, \mathrm{P}_{\mathrm{C} \times \mathrm{Q}}, \mathrm{G}, \mathrm{G}^{*}$, be the same as above. Let $\left\{\mathrm{W}_{\mathrm{n}}\right\}$ be the sequence defined by (4.3). If the set of solutions of (GSEEP) (4.2) is $\Omega \neq \emptyset$, where $\Omega=\left\{\left(x^{*}, y^{*}\right) \in \mathrm{H}_{1} \times \mathrm{H}_{2}:\left(x^{*}, y^{*}\right) \in\right.$ $\mathrm{C} \times \mathrm{Q}: \mathrm{Ax}^{*}=\mathrm{By}^{*}$, the following conditions are satisfied:

(B1) $\left\{\alpha_{n}\right\},\left\{\beta_{n}\right\},\left\{\gamma_{n}\right\} \subset[0,1]$, for any $n \geqslant 0$

$$
\alpha_{n}+\beta_{n}+\gamma_{n}=1
$$

(B2) $\sum_{n=0}^{\infty} \beta_{n}=\infty$ and $\lim _{n \rightarrow \infty} \beta_{n}=0$;

(B3) $\mu_{\mathrm{n}} \in\left(0, \frac{2}{\mathrm{~L}}\right)$, where $\mathrm{L}=\|\mathrm{G}\|^{2}$;

(B4) $\liminf _{n \rightarrow \infty} a_{n} \gamma_{n}>0$.

Then the sequence $\left\{\mathrm{W}_{\mathrm{n}}\right\}$ converges strongly to $\mathrm{W}^{*}=\mathrm{P}_{\Omega} \mathrm{V}_{0}$, which is a solution of (GSEEP) (4.1).

4.2. Application to the general split equality feasibility problem in Banach space

Let $\mathrm{H}_{1}, \mathrm{H}_{2}$ be two real Hilbert spaces and $\mathrm{F}$ is a real smooth Banach space. Let $C_{1, j}$ and $C_{2, j}, j=1,2, \ldots$ be nonempty closed convex subsets of $\mathrm{H}_{1}$ and $\mathrm{H}_{2}$, respectively. The general split equality feasibility problem (GSEFP) in Banach space is defined as follows:

$$
p \in \bigcap_{j=1}^{\infty} C_{1, j}, q \in \bigcap_{j=1}^{\infty} Q_{1, j} \text { such that } A p=B q .
$$

In order to solve problem (GSEFP) (4.4), we propose the following simultaneous type iterative algorithm. 
Algorithm 4.5. For any given $W_{0}=\left(x_{0}, y_{0}\right), v_{0}=\left(v_{01}, v_{02}\right) \in H_{1} \times H_{2}$, the iterative sequence $W_{n} \in H_{1} \times H_{2}$ is generated by

$$
W_{n+1}=\alpha_{n} W_{n}+\beta_{n} V_{0}+\sum_{j=1}^{\infty} \gamma_{n, j} P_{C_{j} \times Q_{j}}\left(I-\mu_{n} G^{*} J_{F} G\right) W_{n}, \quad n \geqslant 0,
$$

where $\left\{\alpha_{n}\right\},\left\{\beta_{n}\right\},\left\{\gamma_{n}\right\}$ are the sequences in $[0,1]$ with $\alpha_{n}+\beta_{n}+\sum_{j=1}^{\infty} \gamma_{n, j}=1$, for all $n \geqslant 0$,

$$
P_{C_{j} \times Q_{j}}=\left(\begin{array}{c}
P_{C_{j}} \\
P_{Q_{j}}
\end{array}\right), G=\left(\begin{array}{cc}
A & -B
\end{array}\right), G^{*}=\left(\begin{array}{c}
A^{*} \\
-B^{*}
\end{array}\right), G^{*} J_{F} G=\left(\begin{array}{cc}
A^{*} J_{F} A & -A^{*} J_{F} B \\
-B^{*} J_{F} A & B^{*} J_{F} B
\end{array}\right) .
$$

Theorem 4.6. Let $\mathrm{H}_{1}, \mathrm{H}_{2}, \mathrm{~F}, \mathrm{C}_{\mathrm{j}}, \mathrm{Q}_{\mathrm{j}}, \mathrm{A}, \mathrm{B}, \mathrm{A}^{*}, \mathrm{~B}^{*}, \mathrm{G}, \mathrm{G}^{*}, \mathrm{P}_{\mathrm{C}_{\mathrm{j}}}, \mathrm{P}_{\mathrm{Q}_{\mathrm{j}}}$ be the same as above. Let $\left\{\mathrm{W}_{\mathrm{n}}\right\}$ be the sequence defined by (4.5). Assum the set of solution of (SEFPP) (4.4) is $\Omega \neq \emptyset$, and the following conditions are satisfied

(B1) $\left\{\alpha_{n}\right\},\left\{\beta_{n}\right\},\left\{\gamma_{n, j}\right\} \subset[0,1]$, for any $n \geqslant 0$

$$
\alpha_{n}+\beta_{n}+\sum_{j=1}^{\infty} \gamma_{n, j}=1
$$

(B2) $\sum_{n=0}^{\infty} \beta_{n}=\infty$ and $\lim _{n \rightarrow \infty} \beta_{n}=0$;

(B3) $\mu_{\mathrm{n}} \in\left(0, \frac{2}{\mathrm{~L}}\right)$, where $\mathrm{L}=\|\mathrm{G}\|^{2}$;

(B4) $\liminf _{n \rightarrow \infty} a_{n} \gamma_{n, j}>0, \forall j \geqslant 1$.

Then the sequence $\left\{\mathrm{W}_{\mathrm{n}}\right\}$ converges strongly to $\mathrm{W}^{*}=\mathrm{P}_{\Omega} \mathrm{V}_{0}$, which is a solution of (SEFPP) (4.4).

\section{Acknowledgment}

The work was supported by the National Natural Sciences Foundation of China (Grant NO: 11661012, 11671101), the National Natural Sciences Foundation of Guangxi (Grant NO: 2015GXNSFAA309018) and Special Funds of Guangxi Distinguished Experts Construction Engineering.

\section{References}

[1] E. Blum, W. Oettli, From optimization and variational inequalities to equilibrium problems, Math. Student, 63 (1994), 123-145. 1, 4.1

[2] C. Byrne, Iterative oblique projection onto convex sets and the split feasibility problem, Inverse Problems, 18 (2002), 441-453. 1

[3] Y. Censor, T. Elfving, A multiprojection algorithm using Bregman projections in a product space, Numer. Algorithms, 8 (1994), 221-239. 1

[4] Y. Censor, T. Elfving, N. Kopf, T. Bortfeld, The multiple-sets split feasibility problem and its applications for inverse problems, Inverse Problems, 21 (2005), 2071-2084. 1, 1

[5] Y. Censor, A. Motova, A. Segal, Perturbed projections and subgradient projections for the multiple-sets split feasibility problem, J. Math. Anal. Appl., 327 (2007), 1244-1256. 1

[6] S.-S. Chang, On Chidume's open questions and approximate solutions of multivalued strongly accretive mapping equations in Banach spaces, J. Math. Anal. Appl., 216 (1997), 94-111. 1, 2.1

[7] S.-S. Chang, H. W. J. Lee , C. K. Chan, W. B. Zhang, A modified halpern-type iteration algorithm for totally quasi- $\phi-$ asymptotically nonexpansive mappings with applications, Appl. Math. Comput., 218 (2012), 6489-6497. 2.4

[8] S.-S. Chang, L. Wang, L.-J. Qin, Z.-L. Ma, Strongly convergent iterative methods for split equality variational inclusion problems in Banach spaces, Acta Math. Sci. Ser. B Engl. Ed., 6 (2016), 1641-1650. 1

[9] S.-S. Chang, L. Wang, X. R. Wang, G. Wang, General split equality equilibrium problems with application to split optimization problems, J. Optim. Theory Appl., 166 (2015), 377-390. 1, 1

[10] C.-S. Chuang, Strong convergence theorems for the split variational inclusion problem in Hilbert spaces, Fixed Point Theory Appl., 2013 (2013), 20 pages. 2.3 
[11] P. L. Combettes, S. A. Hirstoaga, Equilibrium programming in Hilbert spaces, J. Nonlinear Convex Anal., 6 (2005), 117-136. 4.2

[12] L. Gasiński, Z.-H. Liu, S. Migórski, A. Ochal, Z.-J. Peng, Hemivariational inequality approach to evolutionary constrained problems on star-shaped sets, J. Optim. Theory Appl., 164 (2015), 514-533. 1

[13] K. Goebel, W. A. Kirk, Topics in metric fixed point theory, Cambridge Studies in Advanced Mathematics, Cambridge University Press, Cambridge, (1990). 2.2

[14] Z.-H. Liu, Existence results for quasilinear parabolic hemivariational inequalities, J. Differential Equations, 244 (2008), 1395-1409. 1

[15] Z.-H. Liu, X.-W. Li, D. Motreanu, Approximate controllability for nonlinear evolution hemivariational inequalities in Hilbert spaces, SIAM J. Control Optim., 53 (2015), 3228-3244.

[16] Z.-H. Liu, S.-D. Zeng, Equilibrium problems with generalized monotone mapping and its applications, Math. Methods Appl. Sci., 39 (2016), 152-163.

[17] Z.-H. Liu, S.-D. Zeng, D. Motreanu, Evolutionary problems driven by variational inequalities, J. Differential Equations, 260 (2016), 6787-6799. 1

[18] P. E. Maingé, Strong convergence of projected subgradient methods for nonsmooth and nonstrictly convex minimization, Set-Valued Anal., 16 (2008), 899-912. 2.5

[19] A. Moudafi, E. Al-Shemas, Simultaneous iterative methods for split equality problem, Trans. Math. Program. Appl., 1 (2013), 1-11. 1, 1

[20] Z.-J. Peng, Z.-H. Liu, X.-Y. Liu, Boundary hemivariational inequality problems with doubly nonlinear operators, Math. Ann., 356 (2013), 1339-1358. 1

[21] S. Suantai, P. Cholamjiak, Y. J. Cho, W. Cholamjiak, On solving split equilibrium problems and fixed point problems of nonspreading multi-valued mappings in Hilbert spaces, Fixed Point Theory Appl., 2016 (2016), 16 pages. 4.1

[22] H.-K. Xu, A variable Krasnosel'skiü-Mann algorithm and the multiple-set split feasibility problem, Inverse Problems, 22 (2006), 2021-2034. 1

[23] Q.-Z. Yang, The relaxed CQ algorithm solving the split feasibility problem, Inverse Problems, 20 (2004), 1261-1266.

[24] J.-L. Zhao, Q.-Z. Yang, Several solution methods for the split feasibility problem, Inverse Problems, 21 (2005), 1791-1799. 1,1 